\title{
A Study of Hot Rolling Oil with Calcium Carbonate for Stainless Steel Process
}

\author{
Naoshi Shimotomai ${ }^{1)^{*}}$, Hajime Ihara ${ }^{1)}$ and Hidetaka Nanao ${ }^{2)}$ \\ ${ }^{1)}$ Department of Metalworking Fluid Technology, Kyodoyushi Co. Ltd. \\ 2-2-30 Tsujido Kandai, Fujisawa-Shi, Kanagawa 251-8588, Japan \\ ${ }^{2)}$ Department of Chemistry and Bioengineering,Faculty of Engineering, Iwate University \\ 4-3-5 Ueda, Morioka-Shi, Iwate 020-8551, Japan \\ *Corresponding author: naoshi-shimotomai@kyodoyushi.co.jp
}

( Manuscript received 19 October 2009; accepted 30 August 2010; published 15 September 2010 )

\begin{abstract}
Dispersion-type lubricants formulated with calcium carbonate were experimentally studied to achieve improved hot-rolling characteristics of stainless steel. Two types of lubricants; over-based calcium sulfonate dispersed in oil (fluid type; FT) and calcium carbonate dispersed in grease (semi fluid type; ST) were prepared. ST containing larger particles of calcium carbonate exhibited a better lubricity in rolling of steel than FT. Although the particle size of calcium carbonate powder is about $1 \mu \mathrm{m}$, the dispersed state was stable in ST. Following the rolling tests, the surfaces of tribo-films were analyzed using XPS and TOF-SIMS. A lubrication model with calcium carbonate particles was proposed based on the surface analysis.
\end{abstract}

Keywords: hot rolling, stainless steel, seizure, calcium carbonate, grease, over-based calcium sulfonate

\section{Introduction}

Rolling is a metal working process where large pieces of material are deformed between rolls to form desired thinner cross sections. In hot rolling of steel, workpiece materials are heated to about $1000{ }^{\circ} \mathrm{C}$ and rolled under a load of tens of meganewtons. The rolled material surface exposed to the extreme rolling conditions can undergo seizure. It is well known that seizure often occurs in hot rolling of stainless steel possibly because, compared to carbon steel, an oxide film on a stainless steel surface is thinner and nascent surfaces are more likely to be generated during rolling ${ }^{1)}$. Once the work roll seizes with the rolled strip, the seized strip starts to be stacked in layers on the roll surface. As rolling proceeds, repeated friction allows the pieces of the seized strip to break off the roll surface, leading to roll surface damage ${ }^{2,3)}$. Seizure on stainless steel surfaces is not only a cause of such damage, but in shorter intervals of roll replacement or polishing, a slowdown in production and a shorter life of the rolls.

Many attempts have so far been made in the steel industry to prevent seizure of stainless steel by selecting a workpiece or roll material, a rolling speed, a heating temperature and a rolling reduction ${ }^{4-10}$. In addition, several studies about solid lubricants to prevent seizure including iron oxide, black lead, mica, potassium phosphate and engineering plastic powders were reported $^{11-17)}$. On the other hand, Izawa et al. have evaluated an oxalic film to be formed on a roll surface $^{18)}$.

The aim of this study is to prevent seizure in hot rolling of stainless steel with new lubricants. The lubricants were formulated with calcium carbonate as it is inexpensive, easily-available and environmentally-friendly without producing harmful gas by heating.

\section{Experiments}

\subsection{Specimens}

Two lubricants were tested. A semi-fluid type lubricant (ST) was prepared by dispersing calcium carbonate powders having a diameter of $1 \mu \mathrm{m}$ in a grease thickened by lithium 12-hydroxyarate (LiOHSt). A fluid type lubricant (FT) was the oil dispersed with over-based calcium sulfonate (OBCS) having a diameter of about $15 \mathrm{~nm}$. Tables 1 and 2 show the composition and the property of the two lubricants. ST contains 0-60 mass $\%$ of calcium carbonate powder and 1.3 mass $\%$ of LiOHSt. FT contains $0-30$ mass $\%$ of calcium carbonate and 5-16 mass \% of calcium sulfonate. A combination of mineral oils with varying viscosity was added to both lubricants to achieve desired unworked penetration and kinematic viscosity, which were equivalent to NLGI grade of No.000-No.0 and $250-260 \mathrm{~mm}^{2} / \mathrm{s}$, respectively, to facilitate smooth pumping by a regular pump. 


\subsection{Hot rolling test}

The tests were carried out under the conditions described in Table 3. The strips of stainless steel (JIS SUS444: $5.4 \times 25 \times 100 \mathrm{~mm}$ ) and carbon steel (JIS SS400: $4.0 \times 25 \times 100 \mathrm{~mm}$ ) were heated to $1000{ }^{\circ} \mathrm{C}$ and $900{ }^{\circ} \mathrm{C}$, respectively, in a nitrogen atmosphere in an infrared furnace and rolled using a $2 \mathrm{Hi}$ rolling mill. The JIS SKD11 roll was used. The size of the roll is $150 \mathrm{~mm}$ in diameter and $150 \mathrm{~mm}$ in width. The surface roughness of the roll is about $1 \mu \mathrm{m}(R a)$, and is comparable to that of a roll used in actual rolling. In fact, our experiments were started with High Speed Steel (HSS) rolls which are the most widely used roll material in hot rolling. However, the experiments had to be discontinued since HSS rolls had cracks accompanied by seizure when stainless steel strips were rolled. Instead, the subsequent experiments were performed with JIS SKD11 rolls which are typically used in cold rolling so there was almost no crack following seizure.

The lubricants were applied directly onto the roll to form a lubricant film of $5 \mu \mathrm{m}$ Rolling force during the test was measured by a load cell. After testing, the thickness of the rolled strips was measured using a micro gauge. The rolled strip surfaces were analyzed by EPMA, XPS and TOF-SIMS.

\section{Results and discussion}

3.1. Effects of calcium carbonate on carbon steel rolling Although the objective of this study was to prevent seizure in hot rolling of stainless steel, the experiments were started with carbon steel strips. Carbon steel strips are highly resistant to seizure and can provide a definitive comparison between the two lubricants, a dispersed grease with calcium carbonate (ST) and a dispersed oil with over-based calcium sulfonate (FT), under seizure-free conditions. Their lubricity was evaluated based on the measurements of rolling force.

Figure 1 shows rolling force measured in carbon steel rolling. The white circles and the black squares represent rolling force with ST and FT respectively. ST decreased rolling force with an increase in calcium carbonate content. The rolling force stayed fairly constant when it contained more than 30 mass $\%$ of calcium carbonate. As for FT, the rolling force varied to a considerable extent and was greater than that measured with ST having the same amount of calcium carbonate. These results revealed that in hot rolling of carbon steel ST is more effective in achieving stable rolling than FT with the same amount of calcium carbonate.

Table 1 Composition and consistency of ST samples

\begin{tabular}{l|c|c|c|c|c|c|c}
\hline & ST0 & ST10 & ST20 & ST30 & ST40 & ST50 & ST60 \\
\hline $\mathrm{CaCO}_{3}$, mass\% & - & 10 & 20 & 30 & 40 & 50 & 60 \\
\hline LiOHSt, mass\% & 1.3 & 1.3 & 1.3 & 1.3 & 1.3 & 1.3 & 1.3 \\
\hline Mineral Oil, mass\% & 98.7 & 88.7 & 78.7 & 68.7 & 58.7 & 48.7 & 38.7 \\
\hline Unworked Penetration, - & 452 & 449 & 446 & 418 & 394 & 383 & 365 \\
\hline
\end{tabular}

Table 2 Composition and kinematic viscosity of FT samples

\begin{tabular}{l|c|c|c|c}
\hline & FT0 & FT10 & FT20 & FT30 \\
\hline $\mathrm{CaCO}_{3}$, mass $\%$ & - & 10 & 20 & 30 \\
\hline Ca Sulfonate, mass\% & - & 5 & 11 & 16 \\
\hline Mineral Oil, mass\% & 100 & 85 & 69 & 54 \\
\hline $\begin{array}{l}\text { Kinematic viscosity } \\
\text { @ } 40^{\circ} \mathrm{C}, \mathrm{mm}^{2} / \mathrm{s}\end{array}$ & 251 & 254 & 253 & 257 \\
\hline
\end{tabular}

Table 3 Test condition

\begin{tabular}{|c|c|c|}
\hline \multicolumn{3}{|l|}{ Roll } \\
\hline Material & \multicolumn{2}{|l|}{ JIS SKD11 } \\
\hline Dimension & \multicolumn{2}{|l|}{$150 \phi \times 150 \mathrm{~mm}$} \\
\hline $\begin{array}{r}\text { Roughness } \\
\text { (Ra) }\end{array}$ & \multicolumn{2}{|c|}{$1.04 \mu \mathrm{m}$ (Top) $1.01 \mu \mathrm{m}$ (Bottom) } \\
\hline Speed & \multicolumn{2}{|l|}{$0.24 \mathrm{~m} / \mathrm{s}(30 \mathrm{rpm})$} \\
\hline Gap & \multicolumn{2}{|l|}{$3.5 \mathrm{~mm}$} \\
\hline \multicolumn{3}{|l|}{ Strip } \\
\hline Material & JIS SS400 & JIS SUS444 \\
\hline Dimension & $4.0 \times 25 \times 100 \mathrm{~mm}$ & $5.4 \times 25 \times 100 \mathrm{~mm}$ \\
\hline Temperature & $900{ }^{\circ} \mathrm{C}$ & $1000^{\circ} \mathrm{C}$ \\
\hline
\end{tabular}

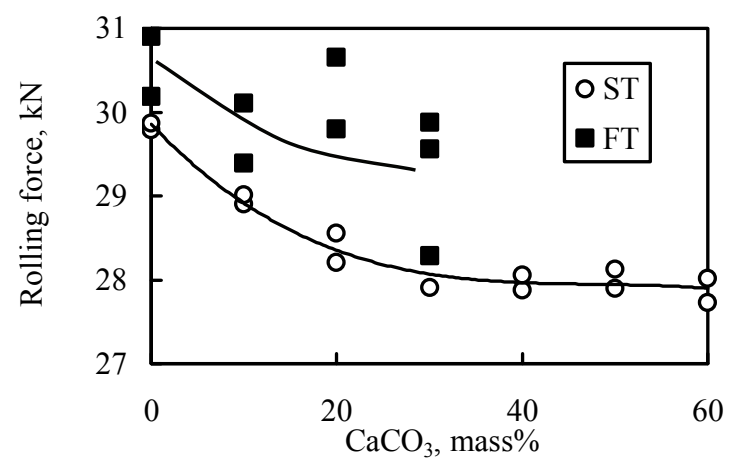

Fig. 1 Rolling force in carbon steel 
3.2. Lubricity of base lubricant in stainless steel rolling

Following the above tests, as a first trial, ST and FT with $30 \mathrm{mass} \%$ of calcium carbonate were evaluated in hot rolling of stainless steel because conventional OBCS generally contains only up to 30 mass $\%$ of calcium carbonate.

As in rolling of carbon steel, lower rolling force was measured with ST (ST30: $52 \mathrm{kN}$, FT30: $66 \mathrm{kN}$ ). Meanwhile, seizure occurred in the stainless steel strips lubricated with FT and ST, but was severer in the strips with FT. In hot rolling of stainless steel, ST exhibited better lubricity to reduce rolling force and seizure than FT.

According to the surface inspection with a microscope, ST with 30 mass $\%$ of calcium carbonate prevented seizure more effectively than FT, but was not capable of completely eliminating seizure. Consequently, STs with calcium carbonate content higher than 30 mass $\%$ were evaluated as a possible solution to improve seizure resistance. It should also be mentioned that no further evaluation was performed with FT.

\subsection{Seizure resistance by calcium carbonate powder}

Hot rolling tests using stainless steel strips lubricated with STs were conducted to study the effects of calcium carbonate content. The calcium carbonate content in STs was changed ranging from 0 to 60 mass $\%$ by 10 mass $\%$ increments.

Figure 2 shows the roll surface after rolling tests. The roll surface lubricated with ST0 having 0 mass $\%$ of calcium carbonate had seizure on most of the surface. However, STs exhibited higher seizure resistance with an increase in calcium carbonate content, and almost no seizure was observed when the content was more than 50 mass\% (ST50, ST60).

Figures 3 and 4 show a correlation between the thickness of rolled strips and calcium carbonate content, and changes in rolling force through rolling time, respectively. Although the roll gap was fixed through the tests, the rolled strip thickness and rolling force decreased with an increase in calcium carbonate content. That means that the high content of calcium carbonate contributes to improve hot rolling characteristics of stainless steel. In addition, Figure 4 indicates that rolling time was reduced as calcium carbonate content decreased even when strips of the same length were rolled. Such a reduction in rolling time, which was associated with increased rolling force, could be explained as follows; the seizure-damaged strip with lower calcium carbonate content was caught up between rolls and can hardly be extended in the rolling direction.

Figure 5 shows the effects of calcium carbonate content on rolling effectiveness. It was found that the rolling force and the reduction were affected by the content of calcium carbonate in ST. Therefore, the effectiveness of ST was evaluated by the ratio of the rolling force and the reduction as shown in Figure 5. STs exhibiting the lower rolling effectiveness were considered to have better lubricity. As for STs with more than 50 mass $\%$ of calcium carbonate, which showed almost no seizure as shown in Figure 2, the rolling force decreased by about $40 \%$ compared to ST without calcium carbonate. It is obvious that the lower rolling force takes less energy required for working.

Comparing the rolling of carbon steel as shown in Figure 1, it is suggested that ST was more effective for rolling of stainless steel than carbon steel. In rolling of carbon steel as follows, where no seizure had occurred, only $7 \%$ reduction in rolling force was achieved by adding calcium carbonate.

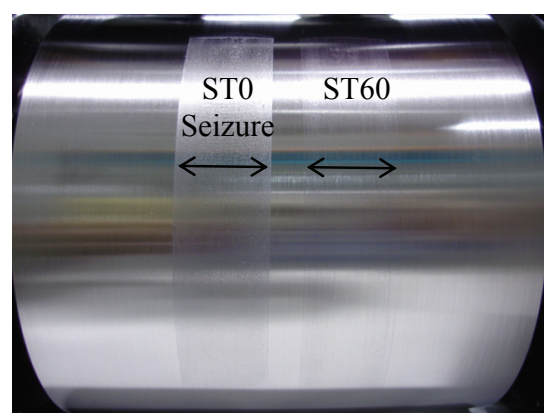

Fig. 2 Roll surface after rolling tests in stainless steel Left:ST0, Right:ST60

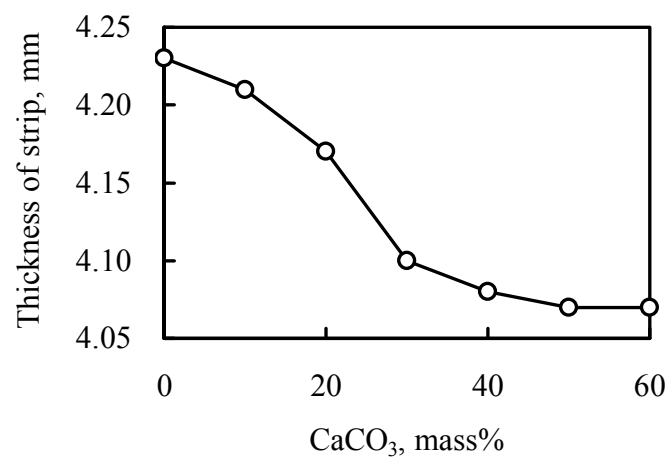

Fig. 3 Effects of calcium carbonate on thickness of rolled stainless strip

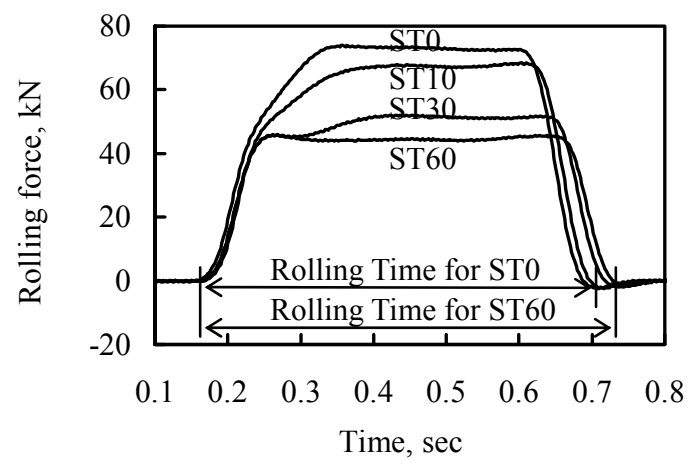

Fig. 4 Rolling force in stainless steel 


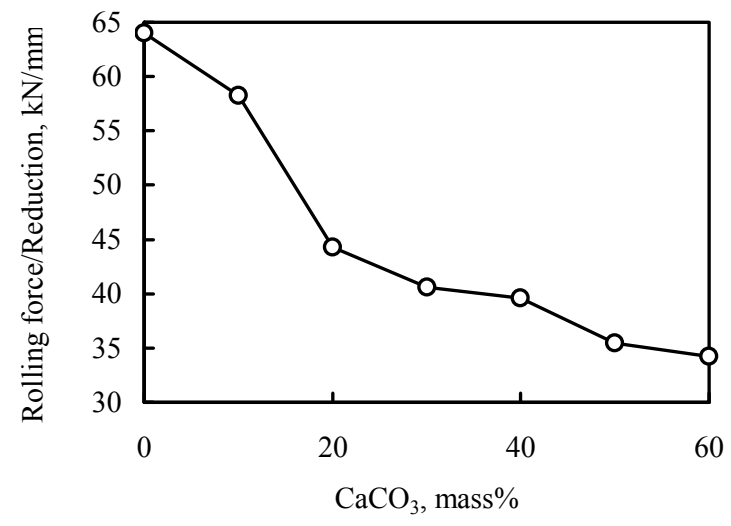

Fig. 5 Effects of calcium carbonate content on the ratio of rolling force to rolling reduction

\subsection{Analysis of rolled strip surface}

The surfaces of stainless steel strips lubricated with ST30 and FT30 were analyzed after rolling to study the lubricating film structure.

First, the film structure was examined by EPMA. Figure 6 shows the EPMA images of each strip surface. ST30 and FT30 strips had only a few percent of Ca. Since EMPA is designed to detect the chemical composition of surface layers to a depth of $1 \mu \mathrm{m}$, the calcium film seemed to be thin.

Second, TOF-SIMS analysis was performed to study the film structure of the top surface. The strip surface was ion-etched to remove organic contaminants and four positions on the surface with several millimeters in distance were analyzed. Figure 7 shows the ion images of total, $\mathrm{Ca}^{+}$and $\mathrm{Fe}^{+}$in the area of $180 \times 180 \mu \mathrm{m}$. ST30 and FT30 strips had $\mathrm{Ca}^{+}$clearly, indicating the presence of Ca film. Comparing the images of $\mathrm{Ca}^{+}$and $\mathrm{Fe}^{+}$, their distributions were not corresponding to each other. This means that the film consists of a mixture of the two components.

Consequently, XPS analysis was performed to study the nano-order film structure. The chemical composition was summarized in Table 4, which shows that ST30 strip contained more $\mathrm{Ca}$, calcium content is estimated as the ratio of $\mathrm{Ca} 2 \mathrm{p}$ to $\mathrm{Fe} 2 \mathrm{p}$, than FT30 strips. In addition, a tribo-film mainly consisting of $\mathrm{Ca}$ was measured with ST30 at a depth of around $1 \mathrm{~nm}$ after etching. In other words, the strip surface lubricated with ST was covered with a thicker tribo-film than that with FT. XPS spectra of $\mathrm{Ca} 2 \mathrm{p}$ and $\mathrm{O} 1 \mathrm{~s}$ also revealed that the main component of the tribo-film was not calcium carbonate but calcium oxide.

TOF-SIMS analysis identified the film structure of the top surface layer and the XPS analysis confirmed that the $\mathrm{Ca}$ film of several $\mathrm{nm}$ was formed with ST. ST30 and FT30 strips had lubricating films of different thickness although both lubricants containe the same amount of calcium carbonate. The lubrication mechanism is schematically demonstrated in Figure 8 to

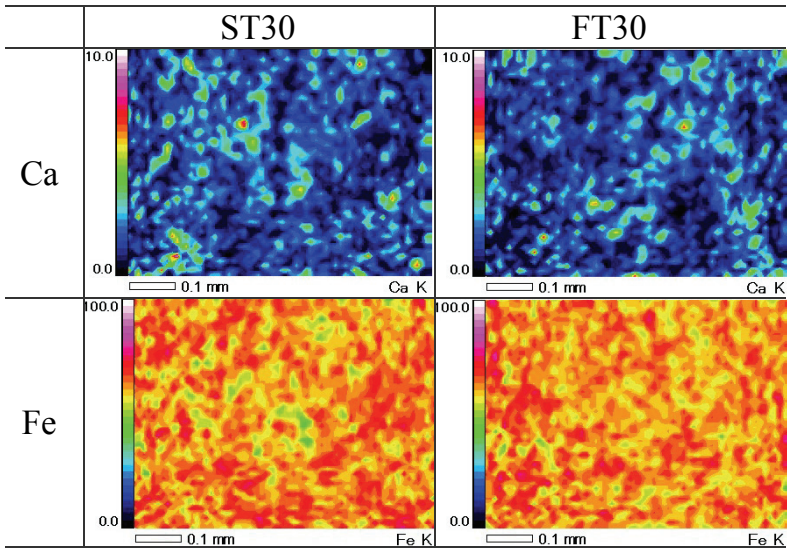

Fig. 6 EPMA images

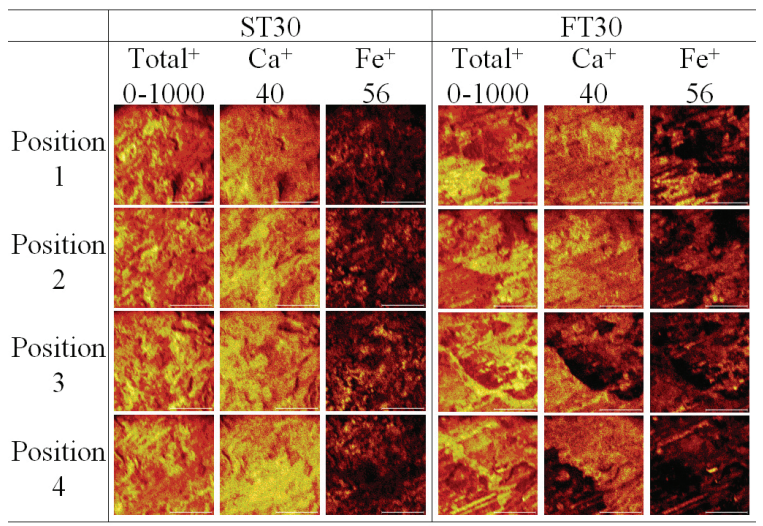

Fig. 7 TOF-SIMS ion images $(180 \times 180 \mu \mathrm{m})$

Table 4 Chemical composition of tribo-films analyzed by XPS

\begin{tabular}{c|c|c}
\hline $\begin{array}{c}\text { Etching } \\
(\mathbf{3 k V ~ 6} \times \mathbf{6})\end{array}$ & $\begin{array}{c}\text { ST30 } \\
(\mathbf{C a 2} \mathbf{2} / \mathbf{F e} 2 \mathbf{p})\end{array}$ & $\begin{array}{c}\text { FT30 } \\
(\mathbf{C a 2} \mathbf{p} / \mathbf{F e} \mathbf{2})\end{array}$ \\
\hline $0 \mathrm{sec}$ & 3.9 & 0.9 \\
\hline $15 \mathrm{sec}(0.2 \mathrm{~nm})$ & 2.8 & 0.7 \\
\hline $67 \mathrm{sec}(1 \mathrm{~nm})$ & 1.9 & 0.6 \\
\hline
\end{tabular}

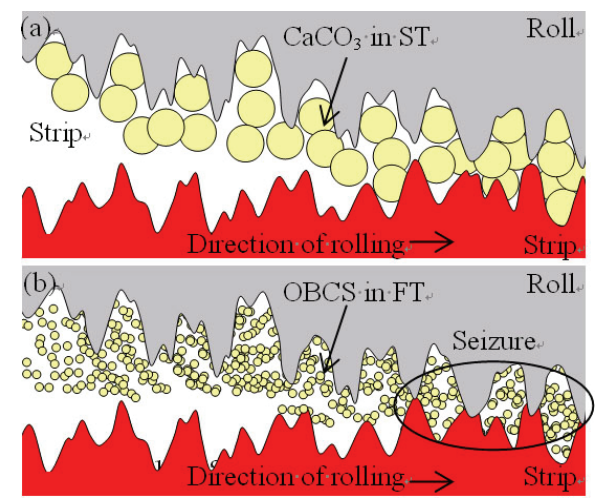

Fig. 8 Lubrication mechanism at the contact of roll / strip with ST(a) and FT(b) 
understand the difference between ST and FT.

A diameter of the calcium carbonate powder in ST was approximately $1 \mu \mathrm{m}$ whereas that of OBCS in FT was approximately $15 \mathrm{~nm}$. The surface roughness of the roll used in rolling tests was approximately $1 \mu \mathrm{m}(R a)$ and of the same order of magnitude as the diameter of the calcium carbonate powder in ST. With these in mind, it should be considered that the calcium carbonate powders were trapped in the surface asperity and aggregated at points of contact leading to less frequent surface contact. OBCS in FT was too small to be trapped and did not prevent surface contact. Thus, matching the diameter of calcium carbonate powders in a lubricant to roll surface roughness can facilitate the effective lubrication.

\section{Application to actual hot strip mill}

Considering all of the above results, the semi-fluid type lubricant with calcium carbonate powder dispersed in grease was evaluated in field trials using stainless angle steel in a hot rolling mill. Figure 9 shows the rolled strip surface. ST improved the surface quality greatly, whereas with a conventional hot rolling oil with a sulfur-containing EP additive, the strip had a poor quality surface and seizure occurred at the edge of the strip. ST showed better surface quality even without the sulfur- containing EP additive.

In general, the important component of hot rolling oil for stainless steel is a sulfur-containing EP additive. Seizure of stainless steel can be prevented with the oil containing a higher concentration of the EP additive. However, the environment should be contaminated by gases evolved from the additive during hot rolling. Here, the newly developed lubricant, ST exhibited better lubricating performance than a conventional lubricant

(a) With ST

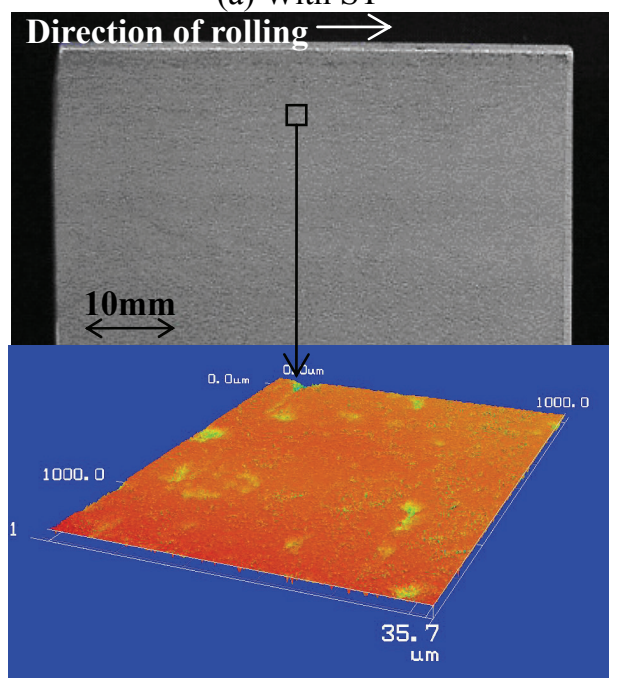

and prevented seizure without sulfur-containing EP additives in hot rolling of stainless steel.

The semi-fluid type lubricant has been used with success in five shape rolling mills in Japan, and is expected to be used in more mills.

\section{Conclusions}

Dispersion-type lubricants formulated with calcium carbonate were experimentally studied to achieve improved hot rolling characteristics of stainless steel. Conclusions from the measurements of hot rolling characteristics of OBCS-dispersed oil (FT) and calcium carbonate powder-dispersed grease (ST) are as follows:

(1) ST greatly prevented seizure of stainless steel in hot rolling even without a sulfur-containing EP additive.

(2) Calcium carbonate having a diameter of $1 \mu \mathrm{m}$, which was dispersed in grease was more effective than OBCS of a several tens nm diameter in preventing seizure.

(3) With an increase in calcium carbonate content, ST exhibited more favorable lubricity and reduced the rolling force as well as the thickness of rolled strips.

(4) Calcium carbonate prevented adhesion of the workpiece material to the roll surface by forming a tribo-film mainly consisting of calcium oxide.

\section{Acknowledgement}

The authors thank for Prof. Shigeyuki Mori and Mr. Kimihiro Kobayashi of Iwate University for their extensive assistance in the XPS and TOF-SIMS analyses.

(b) With conventional hot rolling oil

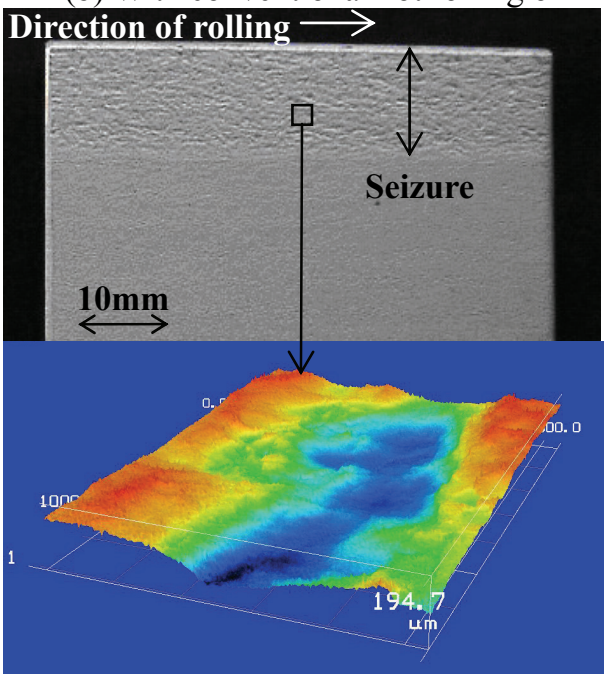

Fig. 9 Surface observation of stainless steel strips rolled with ST(a) and conventional hot rolling oil(b) 


\section{References}

[1] Kato, O. and Kawanami, T., "An Experimental Method for Simulation of Scoring of Rolls during Hot Strip Rolling of Stainless Steel," Journal of the JSTP, 28, 314, 1987, 264-271. (in Japanese)

[2] Kato, O. and Kawanami, T., "Propagation Process of Scoring of Rolls during Hot Strip Rolling of Stainless Steel," Journal of the JSTP, 30, 336, 1989, 103-109. (in Japanese)

[3] Jin, W., Choi, J. and Lee, Y., "Nucleation and Growth Process of Sticking Particles in Ferritic Stainless Steel,” ISIJ International, 40, 8, 2000, 789-793.

[4] Jin, W., Choi, J. and Lee, Y., "Effect of Roll and Rolling Temperatures on Sticking Behavior of Ferritic Stainless Steels," ISIJ International, 38, 7, 1998, 739-743.

[5] Komi, J., Salmon, E., Fischer, F., Peltoniemi, R. and Levonmaa, R., "Effect of Strip Lubrication on Friction in Hot Rolling of Stainless Steel," Proceedings of the $7^{\text {th }}$ International Conference on Steel Rolling Chiba, 1998, 452-456.

[6] Aoki, K., Sato, T. and Azushima, A., "Performance Evaluation of Simulation Testing Machine Developed Newly for Lubricant in Rolling," Proceedings of the $7^{\text {th }}$ International Conference on Steel Rolling Chiba, 1998, 457-460.

[7] Jin, W., Piereder, D. and Lenard, J. G., "A Study of the Coefficient of Friction during Hot Rolling of a Ferritic Stainless Steel," Lubrication Engineering, 58, 11, 2002, 29-37.

[8] Asano, Y., Nishi, T. and Yanagimoto, Jun., "Continuous Heating System using Electric Resistance Heating for the Hot Rolling of Stainless Steels," ISIJ international, 42, 10, 2002, 1112-1118.

[9] Kim, C. and Yoo, K., "The Effect of Roll Gap Oil Lubrication in Hot Rolling of Stainless Steels," Proceedings of $3^{\text {rd }}$ International Conference on Tribology in Manufacturing Processes Yokohama, 2007, 133-138.
[10] Azushima, A., Xue, WeiDong. and Yoshida, Y., "Influence of Lubricant Factors on Coefficient of Friction and Clarification of Lubrication Mechanism in Hot Rolling," ISIJ International, 49, 6, 2009, 868-873.

[11] Nakanishi, T., "Influence of Solid Lubricants on Scoring of Tools in Hot Rolling," Lubrication Engineering, 49, 5, 1993, 365-370.

[12] Umeda, K., Enomoto, U., Muraki, S., Inoue, H. and Uemura, M., "High Temperature Rolling-Sliding Tests at near $1000{ }^{\circ} \mathrm{C}$ for Hot Metalworking," Proceedings of Japan International Tribology Conference Nagoya, 1990, 1755-1760.

[13] Yorifuji, A., Kanari, S., Mochizuki, R., Morioka, N. and Michitani, N., "Deveropment of Disk Shoe Lubrication System for Piercing High Cr Steel Pipes," Proceedings of Japan International Tribology Conference Nagoya, 1990, 1773-1777.

[14] Kihara, N. and Ihara, H., "Deveropment of Hot Rollin Oil," Proceedings of the $1^{\text {st }}$ International Conference on Tribology in Manufacturing Processes Gifu, 1997, 393-396.

[15] Ikeda, J., Inagaki, S., Azushima, A., Xue, Wei-Dong. and Etou, M., "Deveropment of Innovative Lubricants for Hot Rolling with High Reduction," Proceedings of $3^{\text {rd }}$ International Conference on Tribology in Manufacturing Processes Yokohama , 2007, 129-132.

[16] Inoue, T., Yamamoto, H., Watanabe, K., Nishida, K. and Sugiura, T., "Lubricity Characteristics of Particles Mixed with Organic and Inorganic Powder and their Seizure Prevention Effect at High Temperature," Journal of the JSTP, 44, 506, 2003, 267-270. (in Japanese)

[17] Inoue, T., Yamamoto, H., Ataka, M., Takahashi, H., Nishiyama, Y. and Kurahashi, R., "Effect of Solid Lubricants Mixed with Grease on Hot Rolling Lubrcation," Journal of the JSTP, 43, 496, 2002, 411-416. (in Japanese)

[18] Izawa, M., Goto, K., Tsubouchi, K. and Kusaba, Y., "Developmet of Chemical Reaction Coating Lubrication Method for Hot Rolling Work Roll of Stainless-Steel H-Beams," Journal of the JSTP, 43, 494, 2002, 204-208. (in Japanese) 